\title{
Utilização de células-tronco de medula óssea para tratamento de isquemia crítica de membro inferior
}

\author{
U se of bone marrow stem cells to treat critical ischemic limbs \\ José D almo de Araújo, José D almo de Araújo Filho, Emerson Ciorlin, \\ O swaldo Tadeu Greco, Roberto Vito Ardito, Lílian Piron Ruiz, M ilton Artur Ruiz*
}

\begin{abstract}
Resumo
Relatamos o caso de um paciente masculino de 49 anos, portador de oclusão embólica de todas as artérias da perna esquerda. Após múltiplas e fracassadas tentativas de revascularização e, também, simpatectomia lombar em outros serviços, chegou a nós com indicação de amputação no nível de perna. Propusemos o implante de células-tronco autógenas de medula óssea na panturrilha. O bteve-se um excel ente resultado, com a supressão da dor em repouso, melhora da hipotermia e palidez, el evação do índice tornozelo/braço, da velocidade sistólica de pico, dosíndices cintilográficos e angiográficos esensível melhora na granulação no local da amputação do quarto e quinto pododáctilo.
\end{abstract}

Palavras-chave: Células-tronco, terapia regenerativa.

\section{Introdução}

U ma terapêutica regenerativa tem sido buscada há décadas. 0 uso de células-tronco adultas, iniciado há menos de uma década, éuma linha de pesquisa promissora e em plena ebulição no mundo todo.

\section{Relato do caso}

Paciente R. T. M ., 49 anos, branco, masculino, funcionário público, natural de Campo Grande (MS). Atendido em abril de 2005 com queixa de dor isquêmica em repouso no pé esquerdo e necrose em coto de

\footnotetext{
* Instituto de Moléstias Cardiovasculares (IMC), São José do Rio Preto, SP

Artigo submetido em 17.08.05, aceito em 24.08.06.
}

\begin{abstract}
Wereport on the case of a 49-year-old male patient who presented with embolic occlusion of all left leg arteries. After multiple and unsuccessful revascularization attempts and lumbar sympathectomy, he was referred to us with an indication of amputation at the upper third of the leg. We suggested implanting autogenous bone marrow stem cells in his calf. Excellent immediate results were obtained with suppression of rest pain, hypothermia and paleness, elevation of ankle/ brachial index, peak systolic velocities and scintigraphic and angiographic indices. There was also a considerable enhancement of healing at the amputation site of the fourth and fifth toes
\end{abstract}

Key words: Stem cells, regenerative therapy.

amputação do quinto pododáctilo. O s sintomas iniciaram há 6 anos e se intensificaram há 8 meses, tendo sido atendido por diversos especialistas. Foi submetido a uma arteriografia digital de aorta abdominal eartérias dos membros inferiores (2004), que revel ou um aneurisma trombosado de artéria poplítea esquerda, com irrigação distal através de colaterais. N ão havia permeabilidadedenenhumadastrêsartérias daperna. 0 ssinais arteriográficos eram compatíveis com aprisionamento de artéria poplítea bilateral, em que se evidenciava 0 desvio lateral de tais artérias, além da presença do aneurisma à esquerda (Figura 1).

Foi submetido anteriormente a vários procedimentosterapêuticos, como ligadura do aneurisma de artéria poplítea e embolectomia distal, simpatectomia lombar à esquerda eamputação do quinto pododáctilo com debridamentos posteriores. 


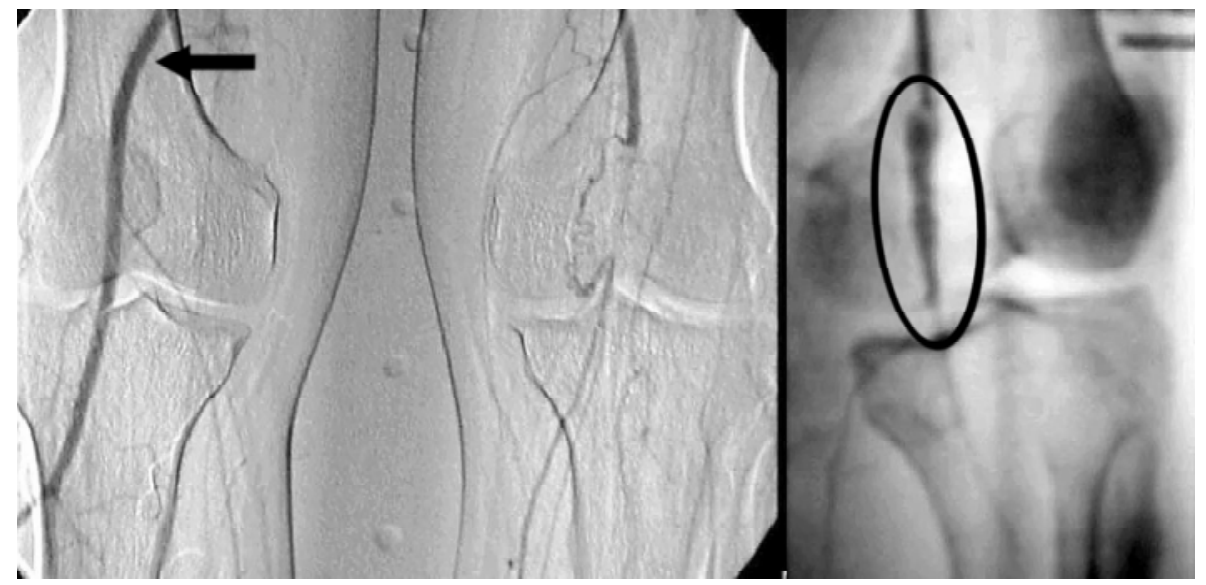

Figura 1 - Aprisionamento de artérias poplíteas, desvio lateral da artéria poplítea direita (seta) e trombose da artéria poplítea esquerda, que se apresentava aneurismática previamente (círculo)

Apresentava antecedentes de hipertensão arterial sistêmica, dislipidemia etabagismo por 30 anos. Estava em uso deinibidoresdaenzimaconversoradeangiotensina e, esporadicamente, estatinas.

Ao exame físico, o paciente apresentava fácies álgica, com diminuição de temperatura em perna e pé esquerdo, ausência de pulsos distais à palpação bilateralmente e índice tornozelo/braço (T/B) 0,85 à direita e 0,40 à esquerda. Apresentava, ainda, necrose do coto de amputação do quinto pododáctilo esquerdo, exposição óssea da epífisemetatarsiana einício denecrosedo quarto pododáctilo.

Após avaliações meticulosas do paciente, através de diversos exames complementares para afastar neoplasias ou doenças sistêmicas, foi proposto o procedimento deinjeção de células-tronco em panturrilha, na tentativa de se obter neovascularização.

Foram obtidos, previamente, a aprovação da Comissão de Ética em Pesquisa da instituição e o consentimento informado do paciente.

0 procedimento consistiu, basicamente, em punção easpiração de $500 \mathrm{ml}$ desangueda medulaóssea dos ossos ilíacos, com posterior processamento para isolar células mononucleares.

A técnica de preparação de células mononucleares foi elaborada pela equipedeterapia celular - método de isolamento de células mononucleares, utilizando-seum meio de densidade (Ficoll) - , baseando-se em diversas referências bibliográficas consagradas ${ }^{1,2}$, e, então, foi elaborado um protocolo operacional padrão para os procedimentos da equipe.

As células mononucleares foram injetadas na musculatura da panturrilha esquerda através de uma grade demarcada com 40 pontos eqüidistantes, nos quais foi injetado $1 \mathrm{ml}$ em cada ponto. 0 total de células mononucleares injetadas foi de 3,6 x $10^{8}$ (Figura 2).

A pós o procedimento, também houve a necessidadedeamputação do quarto pododáctilo esquerdo, com debridamento local no mesmo tempo cirúrgico da injeção de células mononucleares. Foram realizados acompanhamento diário de enzimas musculares - cre-

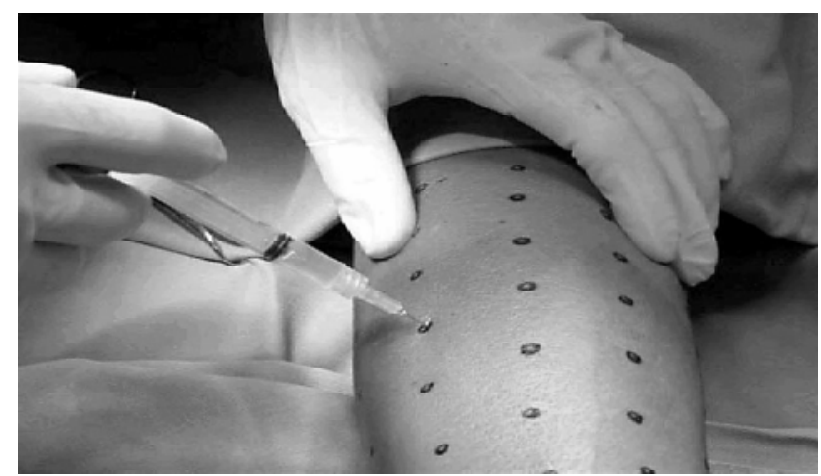

Figura 2 - Injeção decélulas-tronco em panturrilha (grade com pontos marcados) 
atina fosfoquinase (CPK) - até o sétimo dia e curativos com adequada terapia antál gica.

Realizamos, ainda, a comparação da perfusão muscular da perna antes e após o procedimento, através de cintilografia de perfusão, e avaliamos a vascularização local através de arteriografias digitais pré e pós-procedimento. 0 princípio básico do estudo de perfusão com radioisótopos é a relação de proporcionalidade da sua concentração no tecido estudado com o fluxo sangüíneo regional. N o presente caso, foi utilizado para a realização do estudo o traçador Sestamibi (2-metoxi-isobutil-isonitrila), marcado com $20 \mathrm{mC}$ i do agente radioativo T ecnécio $99 \mathrm{~m}$. As imagens dos membros inferiores foram adquiridas em câmara decintilação M illenium M PR, com processamento dasimagen sem estação detrabaIho Entegra. Foram adquiridas imagens de fluxo na projeção posterior dos membros inferiores e, posteriormente, imagens de equilíbrio tardias (até 20 minutos após a injeção), nas projeções anterior e posterior dos membros inferiores. Após a aquisição, foram estabelecidas regiões a serem estudadas e, então, feitas as análises visual e quantitativa da captação do traçador nos membros inferiores bilateralmente. Foram realizados um estudo basal pré-procedimento e estudos seriados após o procedimento.

Simultaneamente, eram determinadoso índiceT/B e a velocidade circulatória através do duplex scan, que era relacionado à velocidade na artéria umeral. $N$ esse estudo com duplex scan, foi utilizado um aparelho Acuson XP-10, com transdutor linear de 7-10 M H z, utilizando software para exames vasculares periféricos e analisando-seospicos develocidadesistólica em pontos definidos para realizar as comparações:

- na artéria braquial - $10 \mathrm{~cm}$ acima da prega do cotovelo, na face medial;

- na artéria tibial anterior - $19 \mathrm{~cm}$ acima do pé;

- na artéria tibial posterior - $25 \mathrm{~cm}$ acima do pé;

- na artéria pediosa - a 17 cm do hálux.

Inicialmente, obtivemos uma elevação da CPK conforme esperado, devido ao procedimento em questão com punções musculares, mas os níveis se normalizaram no quinto dia (Figura 3). H ouve, ainda, aumento de temperatura local em toda a perna esquerda, com diminuição da dor logo nos primeiros dias, reduzindo as necessidades de analgésicos potentes.

Os índices T/B (Figura 4) e pico de velocidade sistólica (Figura 5) mostraram alterações já no quinto

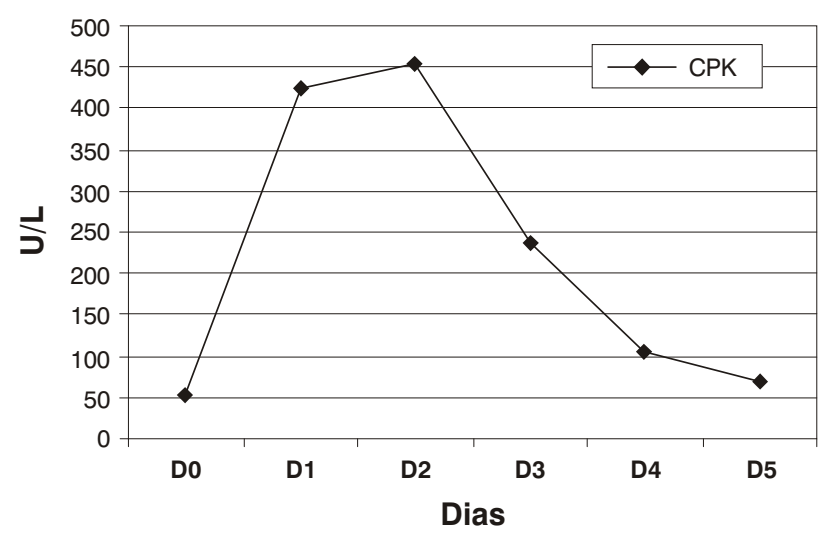

Figura 3 - V Variação da creatina fosfoquinase

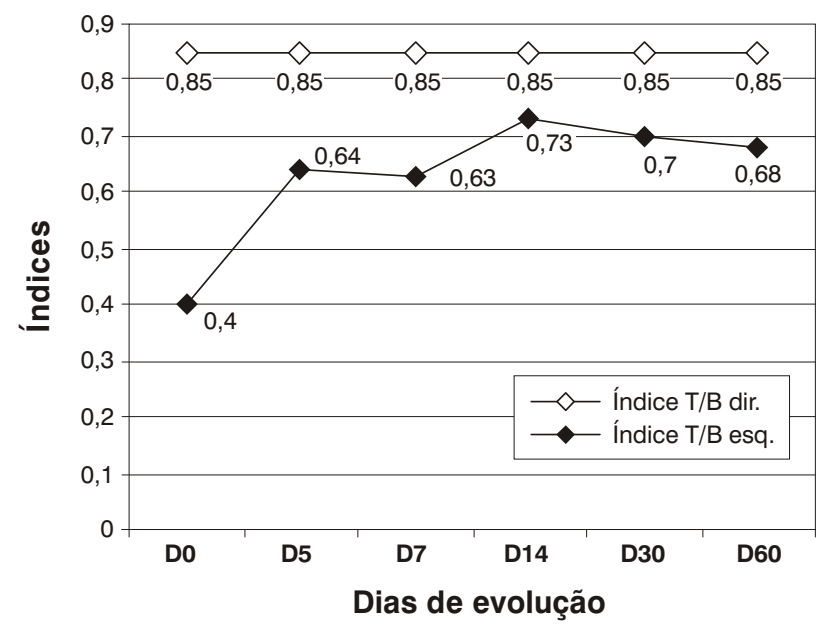

Figura 4 - V Variação dos índices pressóricos dos membros inferiores (índice tornozelo/braço)

dia, com um aumento importante, que se mantém até o momento.

Já no décimo dia após o procedimento, obtivemos uma melhora significativa nos padrões perfusionais cintilográficos, com incremento relativo médio de $51,6 \%$ da quantificação entre os estudos pré e pós-procedimento. Esse incremento semanteveno controleno $35^{\circ}$ dia pós-procedimento (Figura 6).

T ambém observamos um aumento substancial na vascularização da perna e pé esquerdo no 30 이, quando comparamos as arteriografias digitais préepósprocedimento, inclusive com visualização deartérias de maior calibrequenão eram visualizadas anteriormente, agora perfundidas por colaterais (Figura 7). 


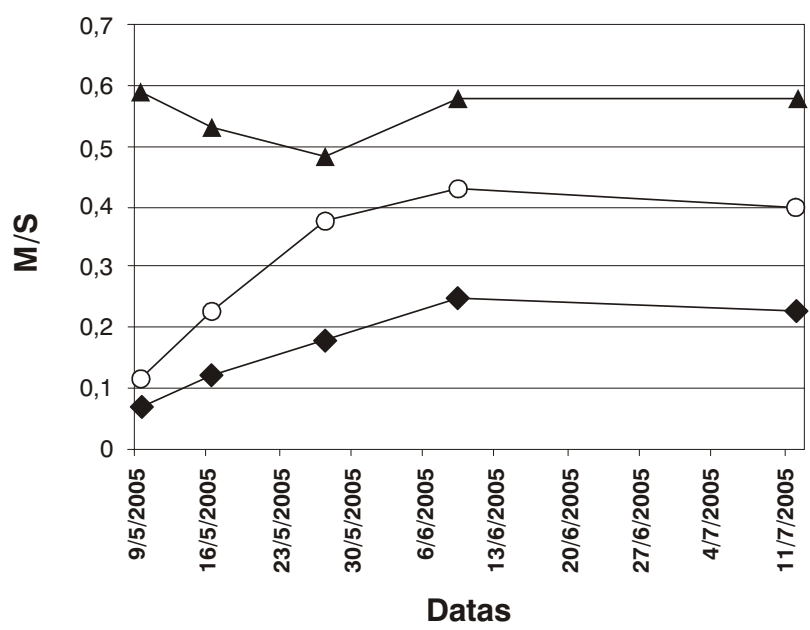

$\longrightarrow$ Artéria braquial $\longrightarrow$ Artéria pediosa - - I Índice artéria pediosa/artéria braquial

Figura 5 - V V ariações da velocidade sistólica de pico

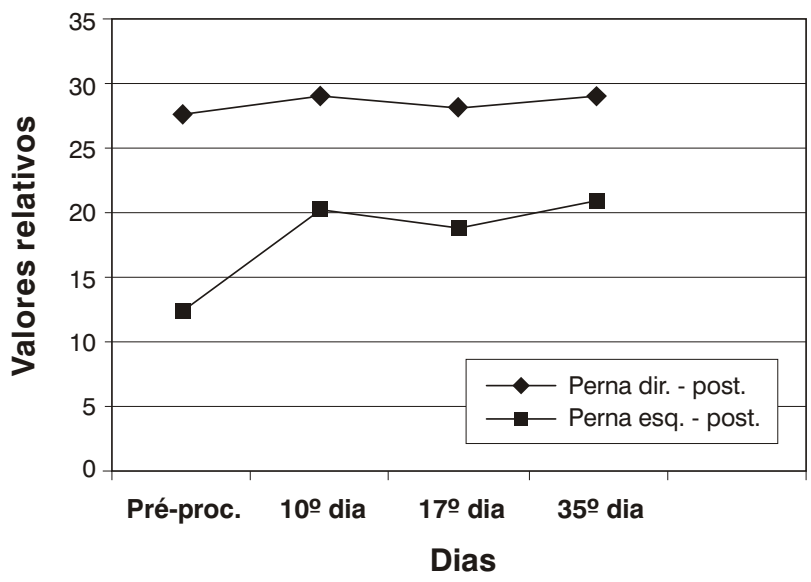

Figura 6 - Análise cintilográfica da perfusão

Esses dados se mantêm, após 7 meses de seguimento, com cicatrização completa da lesão e supressão total da dor em repouso (Figura 8).

\section{D iscussão}

Ainda não se conhece o mecanismo pelo qual as células mononucleares da medula possam produzir novos vasos.
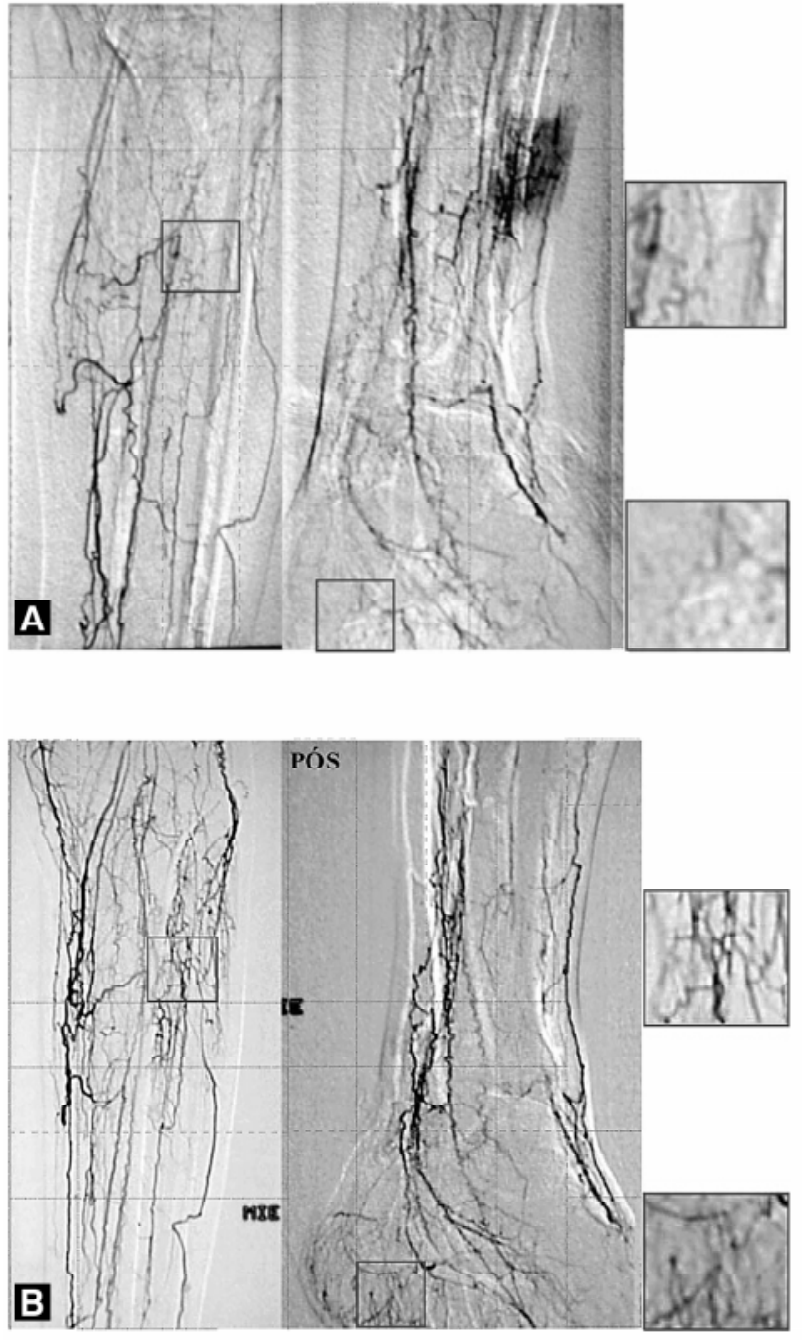

Figura 7 - A) Arteriografia pré-procedimento; B) arteriografia pós-procedimento

Aventa-se a hipótese de que seriam células progenitoras endoteliais, que, uma vez na corrente sangüínea, seriam mobilizadas por substâncias liberadasna zona isquêmica (mili eu-dependent) ${ }^{3}$, que poderiam ser fatores de crescimento endoteliais (vascular endothelial growth factor), fatores de crescimento dosfibroblastos(fibroblast growth factor), citoquinas, angiopoietinas e outros ${ }^{4}$.

0 utra hipótese é de que essas células-tronco possuiriam, elas mesmas, esses fatores de crescimento que concorreriam para a formação de novos vasos, inclusive estimulando células progenitoras "residentes" na região da isquemia (ação parácrina). Ainda uma terceira hipótese sugere que as células-tronco 


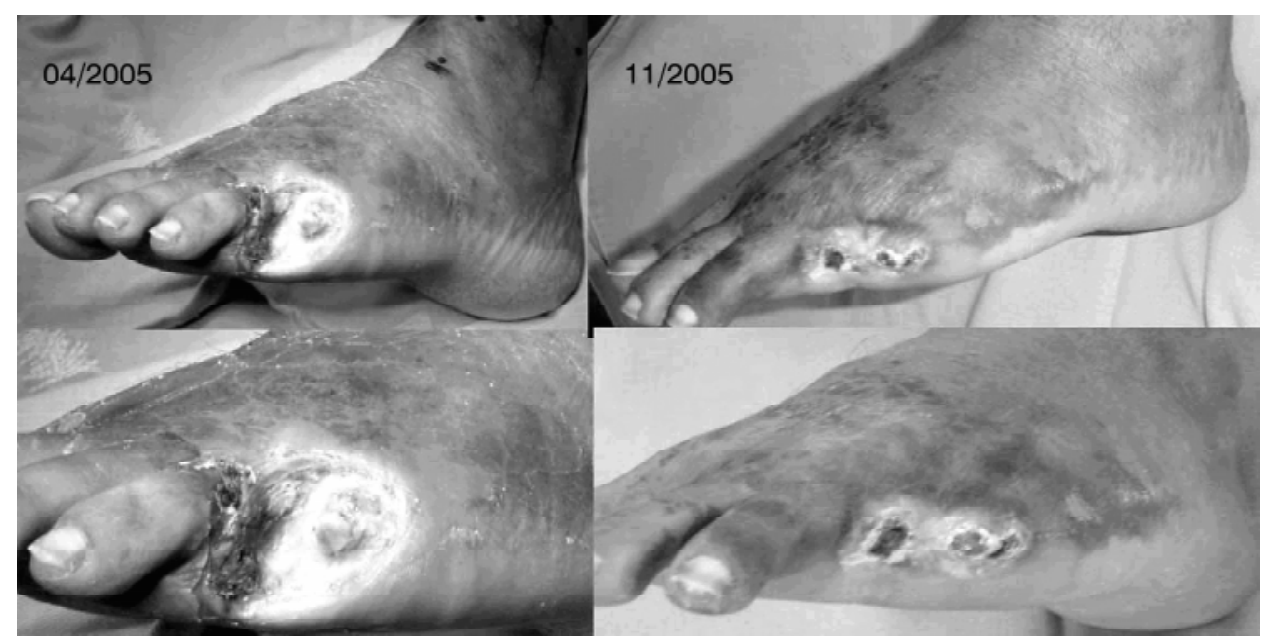

Figura 8 - Evolução da gangrena do pé

melhorariam o funcionamento do endotélio dos vasos remanescentes na região doente, e este endotélio secretaria fatores de estímulo à criação de novos vasos ${ }^{5}$. Tem-se como possível e até provável uma associação dessas três hipóteses.

Essesnovosvasos (neovascularização) seformariam de três maneiras:

a) Angiogênese - capilares que resultariam de brotos que se originariam de vasos já existentes e seriam produzidos pelos fatores já citados ${ }^{6}$;

b) Arteriogênese- aparentemente, a partir da ativação de vasos "adormecidos", embora al guns acreditem na possibilidade de neoformação, a arteriogênese seria estimulada pelas variações no shear stress ${ }^{7}$;

c) V asculogênese- formação denovos vasos ou remodelação de vasos já existentes, por células progenitoras que seriam mobilizadas pela isquemia ${ }^{8}$.

Parece que a arteriogênese é o mecanismo mais efetivo no aumento da circulação (20 a 30 vezes), enquanto a angiogênese aumenta duas a três vezes, e a vasculogênese ainda não foi adequadamente dimensionada? .

N o nosso caso, conseguimos detectar um significativo aumento na circulação por meios indiretos; índice T/B, queaumentou de 0,4 para 0,7; índice de velocidadesistólica de pico, quefoi de 0,22 para 0,396 m/s; por cintilografia, que mostrou aumento de mais de $50 \%$; pela supressão da dor em repouso, antes intensa; e, finalmente, pela melhora na granulação e cicatrização da úlcera isquêmica resultante da desarticulação do quarto e quinto pododáctilo, além da melhora na coloração e temperatura da perna e do pé.

A angiografia feita no 30 으 dia pós-operatório mostrou um consistente aumento da rede vascular. T eve-se o cuidado de fazer o exame pré e pós-operatório com técnicas idênticas, injetando-se a mesma quantidadede contrasteecom a mesma pressão. As comparaçõeseram feitas entre exposições com tempo igual, o que era confirmado pela densidade igual dos troncos arteriais maiores. M ediante uma quadriculação da chapa radiográfica, contavam-se os vasos em cada quadro.

N osso pacienteera relativamentejovem enão apresentava sinais de doença aterosclerótica. Ele sofreu embolização periférica a partir deaneurisma secundário a aprisionamento da artéria poplítea, com obstrução de todas as artérias da perna e necrose do quarto e quinto pododáctilo. As injeções de células-tronco foram feitas diretamente na panturrilha, por duas razões: porque a eficiência seria maior (maior concentração local), e os eventuais efeitos colaterais seriam menores do que se houvesse injeção sistêmica.

O s resultados são muito animadores, mas, obviamente, há necessidade de um número maior de casose randomização. 0 sresultadosno tratamento da miocardiopatia isquêmica são muito positivos ${ }^{10-12}$, enaisquemia de membros há um volume muito grande de trabal hosexperimentais ${ }^{4,13-17}$ etrabalhosclínicos ${ }^{5,18-23}$, 
mostrando resultados muito promissores. $\mathrm{N}$ os trabaIhos, tanto clínicos quanto experimentais, chama-se a atenção para possíveis efeitos colaterais, como formação de tumores, agravamento de retinopatia proliferativa eformação de angiomas, embora nenhum relato de caso com esse tipo de complicação tenha ocorrido. A pesar disso, o protocolo sugere a pesquisa prévia de marcadorestumorais eestudo prévio do fundo deolho. Pesquisam-se também as dislipidemias que supostamente tornariam pior o funcionamento do endotélio, assim como o diabetes de difícil controle e a idade. $\mathrm{A}$ idade avançada comprovadamente diminui as células progenitoras circulantes, que vivem num processo de reconstrução permanente dos tecidos, e esse processo enfraquece com a idade ${ }^{9}$.

D epois que se conseguir provar a segurança e a exeqüibilidade, deve-se passar para estudos randomizados e duplos-cegos, para, então, obter conclusões mais consistentes.

\section{Referências}

1. W ottawa A, Klein G, Altmann H. A method for the isolation on human and animal lymphocytes with Ficoll-U rografin. W ien Klin W ochenschr. 1974;86:161-3.

2. Peper RJ, Zee TW, Mickelson MM. Purification of lymphocytes and platelets by gradient centrifugation. J Lab Clin M ed. 1968;72:842-8.

3. W angJS, Shum-T im D, G alipeau J, Chedrawy E, Eliopoulos $\mathrm{N}$, Chiu RC. M arrow stromal cellsfor cellular cardiomyoplasty: feasibility and potential clinical advantages. J T horac C ardiovasc Surg. 2000;120:999-1005.

4. Al-K haldi A, Al-Sabti H, G alipeau J, LachapelleK. Therapeutic angiogenesis using autologous bone marrow stromal cells: improved blood flow in a chronic limb ischemia model. Ann Thorac Surg. 2003;75:204-9.

5. H igashi $\mathrm{Y}, \mathrm{Kimura} \mathrm{M}, \mathrm{H}$ ara $\mathrm{K}$, et al. Autologous bonemarrow mononuclear cell implantation improvesendotheliumdependent vasodilation in patients with limb ischemia. Circulation. 2004;109;1215-8.

6. Carmeliet P. Angiogenesis in health and disease. $\mathrm{N}$ at $\mathrm{M}$ ed. 2003;9:653-60.

7. de Muinck ED, Simons M. Re-evaluating therapeutic neovascularization. J M ol Cell Cardiol. 2004;36:25-32.

8. Asahara T, M asudaH , T akahashi T, et al. Bonemarrow origin of endothelial progenitor cells responsible for postnatal vasculogenesis in physiological and pathological neovascularization. Circ Res. 1999;85:221-8.

9. Simons M. Angiogenesis wheredo westand now? Circulation. 2005;111:1556-66.

10. Olivares E, Ribeiro VP, W erneck JPS, et al. Cellular cardiomyoplasty with bone marrow cells improves cardiac performance in heart failure induced by heal ed infarct in rats. J Am Coll Cardiol. 2003;41:181A.
11. Dohmann HFR, Perin EC, Borojevic R, et al. Melhora sintomática e da capacidade de exercício após transplante autólogo, transendocárdico, de células mononucleares da medula óssea em pacientes com cardiopatia isquêmica grave, sustentada até 0 sexto mês de evolução. Arq Bras Cardiol. 2005;84:360-6.

12. O rlic D, Kajstura J, Chimenti $S$, et al. Bone marrow cells regenerate infarcted myocardium. N ature. 2001;410:701-5.

13. AsaharaT, M uroharaT, Sullivan A, et al. I solation of putative progenitor endothelial cells for angiogenesis. Science. 1997;275:964-7.

14. Bishop ET, Bell GT, Bloor S, Broom IJ, H endry N F, W heatley $\mathrm{DN}$. An in vitro model of angiogenesis: basic features. Angiogenesis. 1999;3:335-44.

15. Tamarat $\mathrm{R}$, Silvestre JS, Kubis $\mathrm{N}$, et al. Endothelial nitric oxide synthase lies downstream from angiotensin II-induced angiogenesis in ischemic hindlimb. Hypertension. 2002;39:830-5.

16. Iba $\mathrm{O}, \mathrm{M}$ atsubara $\mathrm{H}, \mathrm{N}$ ozawa $\mathrm{Y}$, et al. Angiogenesis by implantation of peripheral blood mononuclear cells and plateletsinto ischemic limbs. Circulation. 2002;106:2019-25.

17. Shintani S, M urohara $T$, I keda $\mathrm{H}$, et al. Augmentation of postnatal neovascularization with autologous bone marrow transplantation. Circulation. 2001;103:897-903.

18. Tateishi-Yuyama $E, M$ atsubara $H, M$ urohara $T$, et al. Therapeutic angiogenesis for patients with limb ischemia by autologous transplantation of marrow cells: a pilot study and randomised, controlled trial. Lancet. 2002;360:427-35.

19. Kawamura A, H orie T, T suda I, et al. Prevention of limb amputation in patients with limbs ulcers by autologous peripheral blood mononuclear cell implantation. Ther A pher Dial. 2005;9:59-63.

20. $H$ uang $P P, L i S Z, H$ an $M Z$, etal. T ransplantation of autologous peripheral blood cells for the treatment of lower limb arteriosclerosis obliterans. Zhonghua Xue Ye Xue Za Z hi. 2003;24:308-11.

21. Yang $X F, W u Y X, W$ ang $H M$, et al. Autologous peripheral blood stem cells transplantation in treatment of 62 cases of lower extremity ischemic disorder. Zhonghua N ei KeZaZhi. 2005;44:95-8.

22. $\mathrm{H}$ uang $\mathrm{PP}$, Li SZ, $\mathrm{H}$ an M Z , et al. Autologous transplantation of peripheral blood stem cells as an effective therapeutic approach for severe arteriosclerosis obliterans of lower extremities. Thromb H aemost. 2004;91:606-9.

23. H ernández Ramirez $P, D$ orticós Balea $E, H$ ernández Padron $C$, et al. T rasplante de células madre autólogas en el miembro inferior isquémico de un paciente con arteriosclerosis obliterante crítica. R ev Cubana $\mathrm{H}$ ematol Inmunol $\mathrm{H}$ emoter. 2005;21:33-8.

Correspondência:

José $D$ almo de Araújo

Rua C astelo D'Água, 3030, Cx. Postal 461

CEP 15015-210 - São J osé do Rio Preto, SP

E-mail: imc@imconline.com.br 